\title{
WILGA Photonics and Web Engineering 2010
}

\author{
Ryszard S. Romaniuk \\ Faculty of Electronics and Information Technology, Warsaw University of Technology
}

Received June 21, 2010; accepted June 21, 2010; published June 21, 2010

\begin{abstract}
SPIE - PSP WILGA Symposium is convened twice a year in January and in May, gathering new adepts of advanced photonic and electronic systems. The event is oriented towards components and applications. WILGA Symposium on Photonics and Web Engineering is well known in the web for its devotion to "young research" promotion under the eminent sponsorship of international engineering associations like SPIE and IEEE and their Poland Sections or Counterparts. WILGA is supported by the most important national professional organizations like KEiT PAN and PSP-Photonics Society of Poland. Apart from young researchers Wilga Symposium is always regularly attended by students' mentors.
\end{abstract}

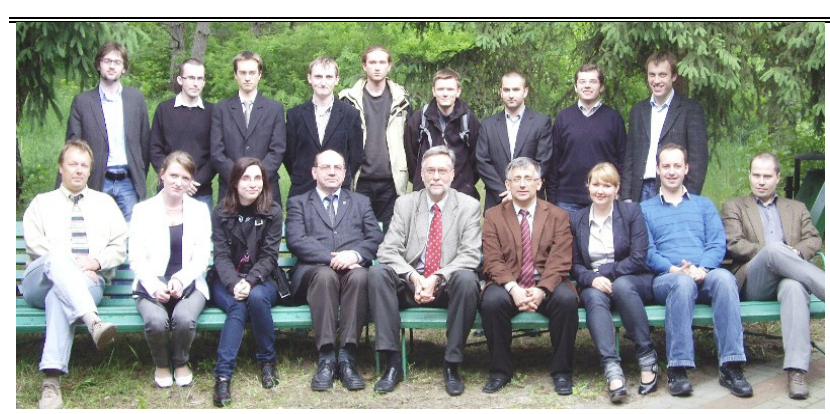

WILGA Session on Photonic Optical Fibers, 25.05.2010, Professors A.W.Domański, R.S.Romaniuk and T.R.Woliński (in the middle, 1 to r) are sitting among photonics Ph.D.students and co-workers.

WILGA - a vivid Symposium for young researchers: Over the last years WILGA Symposium on Photonics Applications has gained a considerable success in Poland and in this geographical region solely by its positive attitude and persistence, high quality of research work, involvement of young organizers, focusing on and actively promoting "young science". The main measure of success has been the crowd of young researchers participating every year for more than a decade, publishing eagerly the results of their work in WILGA SPIE Proceedings. For many of them, now counted in thousands, WILGA was the first presentation and publication experience ever in their research career. WILGA is, in a sense, a diamond cutting factory where the diamonds are gifted young researchers. Summarizing WILGA in a single sentence, one may say that it is a kind of very vivid international Forum of Young Science in Photonics, Advanced Electronics and Internet Engineering. The WILGA Symposium has been organized twice a year since 1998. It has gathered over 4000 young researchers and published over 2000 papers mainly internationally, including more than 900 in 10 volumes of Proc. SPIE published so far. This is an extraordinary achievement for a modest symposium, organized nearly without costs, oriented solely towards young researchers. Not a single event of similar character could be compared to it. This success was possible due to great involvement of young researchers on behalf of their fellows.

Here is a short report on the $25^{\text {th }}$ and $26^{\text {th }}$ Symposia held consecutively in January and May 2010, preceded by some more general impressions. The events took place on 29-30 January at the Faculty of Electronics and Information Technologies of the Warsaw University of Technology and on 24-30 May in Wilga Village near Warsaw. Both meetings gathered around 250 young researchers with over 150 papers presented on current subjects of advanced photonics and electronics issues. The working research Sessions of $26^{\text {th }}$ WILGA 2010 were: photonics, photonic and refractive optical fibers, optoelectronics, applications of optical fibers, integration of electronics, photonics and mechatronics, distributed measurement systems, LHC and CMS at CERN, optics and optoelectronics for astronomy, fundamentals of FPGA-DSP systems, object oriented design of hardware, terabit optical data links, software-hardware co-design, biomedical engineering, computational intelligence of advanced systems, radar and $\mathrm{THz}$ technology, etc. Below you will find a short digest of some of the WILGA 2010 sessions. Some of these presentations are published in this journal and in Proc. of SPIE.

WILGA - EU Framework Programs: from 2004 to 2008 the Symposium was supported by the EU FP6 CARE - Coordinated Accelerator Research in Europe. Since 2009 (to be continued until 2013) it has been supported by the EU $7^{\text {th }}$ FP Project EuCARD - European Coordination for Accelerator Research and Development - coordinated by CERN [cern.ch/eucard]. A special session on EuCARD is organized during WILGA. Participation of young researchers in European projects of global extent is of utmost importance as it opens the doors for them to travel, exchange, learn and study, and finally creatively contribute and generate precious knowledge. WILGA gives a lot of examples of such situations in these above mentioned EU FPs. WILGA sessions on EuCARD usually concern progress in superconducting RF technology (SRF) for accelerators, construction of free electron laser, novel accelerator 
schemes using laser induced plasma wake, building a European FEL network.

WILGA - relations to CERN and DESY: Since its beginning in 1998 Wilga has been closely related to a number of large international research projects concerning experiments in high energy physics. Special relations were always kept with CERN in Geneva - and, in particular, the following projects LHC, PS, SPS, LINAC4, CMS, White Rabbit, Interlocks and Safety Systems. Close relations were established with DESY in Hamburg involving the projects related to superconducting linear accelerators and free electron lasers: TESLA Collaboration, TTF, FLASH, European XFEL.

WILGA - Pi-of-the-Sky project: Wilga Symposium is one of the major publishing sites of the results from the Pi-of-the-Sky project [grb.fuw.edu.pl/pi]. Several dozens of papers have been published since the beginning of the project. The scientific goals of the project are: search for short optical transients of astronomical origin, in particular, search for optical flashes accompanying GRB (Gamma Ray Bursts), study of fast variable stars, participation in multi-wavelength observing campaigns, monitoring activity of blasars and other AGNs. The modes of operation of the observatory are : self-trigger flash recognition in real-time; following Swift, Integral and Glast FoV; reaction to other GCN alerts; observing some objects from GTN and WEBT lists; all sky survey twice a night. The system is located in ASAS site, Las Campanas Observatory in Chile and has been in regular operation since July 2004. The system parameters are as follows: $2 \times 16 \mathrm{CCD}$ cameras $2 \mathrm{kx} 2 \mathrm{k}$ pixels; 5-10s exposures; optics: $\mathrm{f}=85 \mathrm{~mm}, \mathrm{f} / \mathrm{d}=1,2, \mathrm{FOV} \sim 22^{\circ} \times 22^{\circ}$, data stream $128 \mathrm{MBps}$, 5TB/night, on-line analysis due to a multilevel trigger, fast reaction to $\mathrm{CGN}$ triggers via motorized mount which goes to any point in $<1 \mathrm{~min}$., offline next-day analysis up to 14 magnitudo.

WILGA offspring: WILGA Symposium gave birth to a few topical meetings and conferences which then struck out on their own. These include students regional meetings (Opole, Wrocław, Kielce, Białystok, Lublin, Torun and other), of SPIE student chapters, IEEE student branches, but also standalone conferences. Some of these meetings are still held periodically with Wilga, while others gained complete independence. WILGA is very proud of this sort of parenthood as its ideas are proliferating elsewhere. One of such meetings is now fully independent, SPS - Signal Processing Symposium which started at Wilga in 2003.

Optical fibers: An extended session on photonic and refractive optical fibers contained papers on fiber modeling, fundamental optical effects, fiber manufacturing, physical and optical characterization. Several teams were presenting their achievements. A number of essential projects on nonlinear holey optical fibers infiltrated with liquid crystals as done at the Faculty of Physics, WUT. Ten Ph.D. students from this group presented papers on all aspects of liquid crystal filled optical fibers. There were shown new constructions of photonic liquid crystal fibers with inbuilt either nonoptical and/or optical tunability. The fibers were used for construction of various sensors such as: fiber loop sensor for vibration monitoring, hollow core Bragg fiber for bio sensing, liquid crystal fiber interferometers and polarimeters, hybrid fiber sensors for measuring of thermal and mechanical stress. Some of these liquid crystal fibers were manufactured at the Fiber Optics Laboratory of UMCS University in Lublin, under the leadership of the late prof. Jan Rayss and dr Jan Wójcik. The biggest laboratories doing research on complex photonic liquid fibers including classical ones, soft glass, non-silica glass, liquid crystal, nonlinear, perturbated, etc are at the Faculty of Physics, WUT under the leadership of Prof. Andrzej Domański and Prof. Tomasz Woliński, also at the Wrocław Univ. of Technology - Prof. Krzysztof Abramski, Prof. Wacław Urbańczyk. Strong technological laboratories of optical fibers are also located at the Białystok Univ. of Technology and at ITME in Warsaw. Glass for optical fibers is researched at AGH in Kraków - Prof. Jan Wasylak.

Optoelectronics and photonics applications are one of the main subjects of WILGA. Recently, biomedical applications have been added to environmental and industrial ones, not mentioning research and test. A team under the leadership of Dr. Michał Borecki from IMIO WUT presented a fiber optical and physio-chemical analysis system of organic and biological fluids like milk, oils, alcohols, etc. A very interesting on-line real-time measurement system was build, based on optical fiber capillary, checking the fertility in cows. Another paper from Prof. A. Domański's team presented optical tomography of female breasts versus X-ray tomography performed on breasts phantoms with implanted optical inhomogeneities. A session on applications of advanced electronic and photonic systems contained nearly twenty papers on the following subjects: building of a miniature quadro-copter and lunar rover with laser ranging; control system development in robotics; minimal-energy functional systems combined with energy harvesting technology including optical; image recognition for the purpose of road traffic analysis, safety and protection (registration recognition); safe, reliable and ultra-stable power mains for biomedicine; power supplies for photomultipliers; 3D laser scanners; and other. The electronic systems with energy harvesting capability use all possibilities to recover energy from the environments they reside in, i.e. temperature differences, optical illumination, etc. 
Complex systems are potentially a very rich field of novel applications of photonics, electronics and IT systems. An extended session on the subject was organized by Prof. S. Jankowski of WUT and his Ph.D. students. The major research concern of this group is data classification using diversified theoretical models like mutual information, support vector machine, complex statistics, focused correlations, etc. Massive data are gathered from networks of photonic and electronic sensors.

Integration of photonic hardware and software: The session devoted to object design of hardware and software concerned optimization of interaction, and task sharing between these two system layers. New questions were asked associated with object approach to hardware design in such a way as to obtain the best fit between the corresponding object structures in both layers. Automation of optimal complex code generation was considered in $\mathrm{C}++$, VHDL and MatLab script. The area embraces such research as: integration of photonic (electronic and mechatronic) hardware and software, functions sharing between hardware and software, functions exchange, configurability, optimization of available physical system resource usage. This session embraced also architectures for novel, efficient FPGADSP solutions and very fast $\mathrm{Tb}$ optical data transmission.

WILGA 2010 awards for the best student presentation

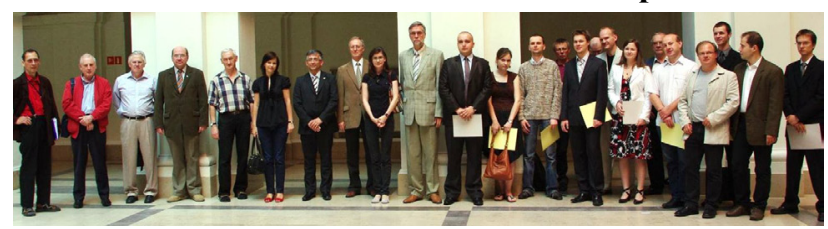

SPIE-PSP award ceremony for the best student paper presentation, 18.06.20010, Main Hall, Faculty of Physics, WUT. Awardees, PSP Board and Faculty Dean -Prof. R. Bacewicz.

The winners are: I-Ph.D. students: 1- G. Kasprowicz, ISE WUT; Determination of beam intensity and position in a Particle Accelerator, 2- P. Makowski - Faculty of Physics WUT; Degree of polarization fading of light passing through birefringent medium with optical axis variation, 3- ex aequo K. Lawniczuk, TPSA and IMIO WUT; Design of integrated photonic transmitter for application in FTTH systems, and - K. Futera, ITR Institute and Mechatronics WUT; Printed electronics on flexible and glass substrates, II-M.Sc. students: 1- P. Obroślak, ISE PW; Digital noise reduction for CCD cameras, 2- P. Florczyk, IMIO WUT; Fiber laser with loop reflector, 3- A. Manerowska ISE WUT; On exploration of medical data base, 4- P.Więckowski, ISE WUT; Master Oscilator DOOCS Server, 5- A. Zagoździńska, ISE WUT; Object oriented programming in VHDL with the use of component internal interface. The winners were presented with SPIE and PSP diplomas and obtained membership privileges.
WILGA tendencies and perspectives: It has to be remembered that WILGA is different from a typical conference. To assess the short-term perspectives of WILGA one has to ask young researchers if this sort of intermediate level meeting is of any aid or meaning to them. Time changes and so does Wilga. A tendency has been observed that particular university teams arriving at Wilga come only for their and adjacent sessions and then go away, not staying longer as they used to. This small change means a lot to Wilga. There were famous night research sessions and discussions around the grill sponsored by IEEE, which grouped a large crowd of young scientists from different university centers. Now the late night groups are mainly from a single or, at most, two or three universities. The participation of young researchers in Wilga is now statistically smaller than it was several years ago (350:150). Also the status of Proc. SPIE (and any other conference proceedings like IEEE and OSA) has changed. The research funding agencies do not fully accept publications in the proceedings preferring papers from peer-reviewed journals as attachments to periodic technical reports - justifying the expenditures. This strongly influences the decisions, where to publish and in what events to participate. WILGA gave birth to several other meetings of young researchers. Local research communities sometimes prefer to participate in a local event (less travel and less money and time) organized in the style taken over from WILGA. WILGA Symposium perspectives seem to be bright, despite all those positive and not so positive developmental tendencies discussed above. During these nice annual meetings in the countryside, far from the participants' home laboratories, WILGA organizers have been able to observe that the need in young researchers to meet with alike fellow scientists has remained so strong that the demand for such meetings will hopefully not cease.

WILGA SPIE-PSP 2011 Symposium plans are accessible on the WILGA web. The papers will be published in SPIEDL and SPIE Proceedings. The organizers of WILGA2011 invite warmly young researchers and students to submit their papers and join the international SPIE, PSP and IEEE young researcher communities. Communications with WILGA organizers and paper submissions are open at photonics@ise.pw.edu.pl.
References
[1] Wilga2002-Proc.SPIE 5125; [2] Wilga2003-Proc.SPIE 5484.
[3] Wilga2004-Proc.SPIE 5775; [4] Wilga2005bis-Proc.SPIE 5948.
[5] Wilga2005-Proc SPIE 6159; [6] Wilga2006-Proc.SPIE 6347.
[7] Wilga2007-Proc.SPIE 6937; [8] Wilga2008-Proc.SPIE 7124.
[9] Wilga2009-Proc.SPIE 7502; [10] Wilga2010-Proc.SPIE 7376.
[11] WILGA web page: $h$ ttp://wilga.ise.pw.edu.pl.
[12] WILGA WIKI: http://pl.wikipedia.org/wiki/SympozjumWilga. 